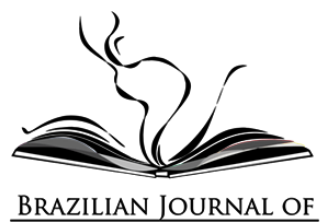

\title{
POLÍTICAS DE TRANSFERÊNCIA DE RENDA E DE ASSISTÊNCIA NO BRASIL: DESCONTINUIDADES RECENTES E OS DESAFIOS COLOCADOS PELA COVID-19
}

\author{
POLÍTICAS DE TRANSFERENCIA DE INGRESOS Y ASISTENCIA EN BRASIL: \\ DISCONTINUIDADES Y DESAFÍOS RECIENTES PLANTEADOS POR COVID-19
}

CASH TRANSFER AND ASSISTANCE POLICIES IN BRAZIL: RECENT DISCONTINUITIES AND CHALLENGES POSED BY COVID-19

Sergio Simoni Junior iD Universidade Federal do Rio Grande do Sul, Brasil

Resumo: Este artigo analisa aspectos da implementação do Auxílio Emergencial no Brasil, criado para combater as crises sanitária, econômica e social acarretadas pela pandemia de Covid-19. Este benefício trouxe desafios para o futuro de políticas permanentes de transferência de renda com vistas à superação de vulnerabilidades, expressando dilemas também enfrentados por outros países da América Latina. Para além da importância da elevação da cobertura e dos valores dos benefícios, ressaltam-se dois aspectos cruciais que têm sido negligenciados pelas discussões correntes e que se revelaram precários no Auxílio Emergencial: a importância de uma efetiva articulação federativa e de um cadastro de beneficiários com informações abrangentes de suas condições de vida. Os resultados obtidos a partir de modelos estatísticos aplicados ao nível municipal revelam que parte da magnitude do grupo de "invisíveis", pessoas até então ausentes dos registros governamentais, é explicada pela desidratação recente das estruturas da política de assistência social, ou seja, por processos de policy drift. Conclui-se que a crise da pandemia poderia ter sido combatida com maior rapidez caso esta política social não estivesse defasada, e argumenta-se que a efetividade futura das políticas 'Professor de Ciência Política e de Políticas Públicas da Universidade Federal do Rio Grande do Sul.
Pós-doutorando vinculado ao CESOP/UNICAMP no âmbito do INCT "Instituto da Democracia e da
democratização da Comunicação". Doutor em Ciência Política FFLCH/USP, mestre em Ciência Política e
graduado em Ciências Sociais pela mesma instituição. E-mail: sergiojr_Ssi@oyahoo.com.br 
de transferência de renda depende da retomada dos instrumentos do Cadastro Único de Programas Sociais.

Palavras-chave: Covid-19; Políticas de Transferência de Renda; Programa-Bolsa-Família; Sistema Único de Assistência Social; Policy Drift.

Resumen: Este artículo analiza aspectos de la implementación de lo Auxilio de Emergencia en Brasil, creado para combatir la crisis de salud, económica y social provocadas por la pandemia de Covid-19. Este beneficio trajo consigo desafíos para el futuro de las políticas permanentes de transferencia de ingresos orientadas a la superación de vulnerabilidades, expresando dilemas también enfrentados por otros países latinoamericanos. Más allá de la importancia de elevar la cobertura y los valores de los beneficios, se destacan dos aspectos cruciales que han sido desatendidos por las discusiones actuales y que resultaron precarios en lo Auxilio de Emergencia: la importancia de una articulación federativa efectiva y de un registro de beneficiarios con información completa sobre sus condiciones de vida. Los resultados obtenidos de modelos estadísticos aplicados a nivel municipal revelan que parte de la magnitud del grupo "invisible", personas hasta entonces ausentes de los registros gubernamentales, se explica por la reciente deshidratación de las estructuras de política asistencial, es decir, por procesos de policy drift. Se concluye que la crisis pandémica podría haberse combatido más rápidamente si esta política social no hubiera quedado obsoleta, y se argumenta que la eficacia futura de las políticas de transferencias de ingresos depende de la reanudación de los instrumentos del Registro Único de Programas Sociales.

Palabras clave: Covid-19; Políticas de Transferencia de Ingresos; Programa-Bolsa-Família; Sistema Único de Asistencia Social; Policy-Drift.

Abstract: This article analyzes aspects of the implementation of the Emergency Aid in Brazil, created to combat the health, economic and social crises brought on by the Covid-19 pandemic. This benefit brought challenges for the future of permanent cash transfer programs aimed at overcoming vulnerabilities, expressing dilemmas also faced by other Latin American countries. In addition to the importance of increasing coverage and benefit amounts, two crucial aspects that have been neglected by current discussions and that have proven to be precarious in Emergency Aid are highlighted: the importance of an effective federal coordination and of a registry of beneficiaries with comprehensive information on their living conditions. The results obtained from statistical models applied at the municipal level reveal that part of the magnitude of the group of 
"invisibles," people until then absent from government records, is explained by the recent drift of social assistance policy structures. It is concluded that the pandemic crisis could have been fought more quickly if this social policy had not been outdated, and it is argued that the future effectiveness of cash transfer programs depends on the resumption of the instruments of the Cadastro Único de Programas Sociais.

Keywords: Covid-19; Cash Transfer Programs; Bolsa-Família Program; Unique Social Assistance System; Policy-Drift

DOI:10.11606/issn.1676-6288.prolam.2021.186413

Recebido em: 31/05/2021

Aprovado em: 25/10/2021

Publicado em: 29/10/2021

\section{Políticas de transferência de renda e de assistência no Brasil: descontinuidades recentes e os desafios colocados pela Covid-19²}

\section{Introdução}

Os impactos da pandemia de Covid-19 colocaram no centro das atenções de governos, de organismos internacionais e da sociedade como um todo as políticas públicas de garantia de renda. Em um contexto no qual o distanciamento social era a medida mais eficiente para controlar a propagação do vírus, antes da formulação e disseminação de vacinas, a paralisação de grande parte das atividades econômicas implicou em elevadas perdas de renda para as famílias, particularmente aquelas inseridas no mercado informal. O fortalecimento das políticas sociais existentes e a criação de novas medidas tornaram-se cruciais para a minimização das diversas crises desencadeadas pela pandemia.

A América Latina se caracterizou nos últimos anos pela inovação neste setor de políticas, particularmente nos programas de transferência de renda condicionada, adotados por quase todos os países da região.

\footnotetext{
${ }^{2}$ Agradeço as leituras e sugestões de Maria Clara Oliveira, Tiago Oliveira e do(a)s pareceristas anônimo(a)s da
} revista. 
Estimativas do ano de 2017 apontam que cerca de 20\% da população do continente era coberta por um benefício desse tipo (ABRAMO; CECCHINI; MORALES, 2019). Ainda que cada programa encerre especificidades, essas políticas públicas se caracterizam pela transferência de renda direta e regular para famílias pobres, exigindo contrapartidas relacionadas a cuidados médicos de gestantes e recém-nascidos, e frequência escolar de crianças. A existência de um cadastro com informação dos atuais e potenciais beneficiários e de instrumentos de cooperação intergovernamental, particularmente nos países federativos, são aspectos importantes do desenho e da engrenagem destas políticas sociais.

Um caso de grande sucesso é o Programa Bolsa-Família (PBF) brasileiro, formulado no final de 20033. Em meados de 2019, o programa atingia cerca de 14 milhões de famílias (IPEA, 2021), em torno de $25 \%$ da população total, com benefício em média de US\$35,004 por família. Há muitos anos o Programa vem sendo submetido a diversas avaliações que, de modo geral, mostram seu impacto na queda da pobreza e da desigualdade (SOUZA et al., 2019), da mortalidade infantil (RASELLA et al., 2013) e em outras dimensões. Além disso, existem evidências de que o PBF também se mostra importante para a economia local de municípios pequenos (DENES; KOMATSU; MENEZES-FILHO, 2018), e gera dividendos eleitorais para o partido que o formulou (ZUCCO; POWER, 2013; SIMONI JR., 2021).

A responsabilidade pelo Programa é do governo federal, mas a implementação é compartilhada com municípios ${ }^{5}$, principalmente no cadastramento de elegíveis e no acompanhamento de condicionalidades (BICHIR, 2016a; PAES DE BARROS; CARVALHO; MENDONÇA, 2009). A inscrição se dá pelo Cadastro Único de Programas Sociais (Cadúnico), instrumento de coleta de dados e informações de famílias em situação de

\footnotetext{
${ }^{3}$ Durante o governo de Luiz Inácio Lula da Silva (PT). O Programa se manteve nos governos seguintes, mesmo os controlados por Michel Temer (MDB) (2016-2018), que assumiu após impeachment de Dilma Rousseff (PT), e Jair Bolsonaro (sem partido) (2019-), ambos com agendas que primam por maior controle de gastos públicos. ${ }^{4}$ Os valores monetários neste artigo estão atualizados e convertidos para a cotação do dólar em dezembro de 2020 ( $R \$ 5,189)$.

${ }^{5}$ Os estados também têm papel, ainda que reduzido, na operacionalização do PBF.
} 
pobreza, que também serve para selecionar beneficiários para outras políticas públicas além do PBF. Ao longo da sua trajetória, o PBF se articulou, ainda que com tensões, com os serviços e as estruturas institucionais do Sistema Único de Assistência Social (SUAS) (PAIVA; FALCÃO; BARTHOLO, 2013; BICHIR, 2016b), que abrange um amplo conjunto de serviços socioassistenciais, no qual os municípios são também atores centrais. Dessa forma, o PBF se tornou "carro-chefe" da rede de proteção social brasileira (SILVA; YASBEK; DI GIOVANNI, 2014).

No começo de 2020, a Organização Mundial da Saúde declarou estado de pandemia devido à disseminação da Covid-19, doença causada pelo vírus Sars-Cov-2. Logo em março, o governo federal, liderado por Jair Bolsonaro 6 (sem partido), manifestou a intenção de criar uma política emergencial de transferência de renda7. O Congresso se antecipou e liderou a formulação da Renda Básica Emergencial (RBE), também conhecida como Auxílio Emergencial ${ }^{8}$, com benefícios da ordem de US\$115 até US\$230 mensais, a depender da composição da família, para pessoas de baixa renda fora do mercado de trabalho formal. Constituíram-se três grupos de beneficiários: (i) as famílias que já recebiam o PBF, que migraram automaticamente para esse novo benefício nos casos em que isso era mais vantajoso, (ii) os demais inscritos no Cadúnico, que tiveram análise imediata de sua elegibilidade; (iii) as pessoas ausentes do Cadúnico, mas que se encaixavam nos critérios estabelecidos. Tecnicamente chamado de Extracad no registro oficial do governo, este segmento, que recebeu informalmente pela imprensa a alcunha de "invisíveis"9 e necessitou se inscrever num cadastro virtual criado para este fim pela Caixa Econômica Federal (CEF), formou o grupo majoritário, com cerca de 38 milhões de pessoas. Neste processo de implementação da RBE, a estrutura institucional e federativa do Sistema Único de Assistência Social

\footnotetext{
${ }^{6}$ Bolsonaro foi eleito em 2018 com uma plataforma de extrema-direita, e seu comportamento na pandemia se caracterizou pelo negacionismo e prescrição de medicamentos ineficazes (BASSANI, FABRIS; SIMONI JR., 2021).

${ }^{7}$ Paralelamente, o governo formulou o Programa Emergencial de Manutenção do Emprego e da Renda, que permitiu a redução de jornada de trabalho e de salários ou a suspensão temporária do contrato formal de trabalho, com pagamento de auxílio financeiro pelo governo federal, após uma malograda tentativa de introduzir uma política de suspensão de contratos sem nenhuma contrapartida aos trabalhadores.

${ }^{8}$ Os dois termos serão usados aqui indistintamente.

${ }^{9} \mathrm{https}: / /$ bit.ly/3oUQ7a2. Acesso em: 13 out. 2021.
} 
(SUAS) não foi utilizada (IPEA, 2021), o que gerou alguns problemas e embates, conforme se falará adiante.

Dada a incerteza quanto à duração da crise, o benefício foi inicialmente implementado por apenas três meses. No entanto, passou por uma prorrogação e serviu de base para um nova política pública em moldes semelhantes ${ }^{10}$, ainda que com valor cortado pela metade, de tal modo que se pode dizer que o Auxílio Emergencial, em diferentes versões, vigorou de abril a dezembro de 2020. Em 2021, o Executivo editou uma Medida Provisória (MP) criando o "Auxílio Emergencial 2021", com quatro parcelas a partir de abril, reduzindo de novo o público beneficiário e, principalmente, o valor do benefício"n. Em julho, finalmente, foi editada uma nova prorrogação nos mesmos parâmetros até outubro de 2021.

O impacto da RBE na redução da pobreza (BARBOSA; PRATES, 2020) e inclusive na reversão da crise econômica provocada pela pandemia (COSTA; FREIRE, 2020) geraram debates entre o governo, especialistas e setores da opinião pública quanto ao futuro do PBF após o fim do Auxílio Emergencial. As polêmicas giram em torno dos limites e possibilidades do aumento do valor médio do benefício, que chegou a superar quatro vezes o valor do PBF, e do alargamento das condições de elegibilidade do Programa para as camadas de "invisíveis", dado os constrangimentos da responsabilidade fiscal: a RBE gastou cerca de US\$ 58 bilhões em 2020, dispêndio possível devido à aprovação de emenda à Constituição criando o chamado "Orçamento de Guerra", instituindo um regime extraordinário fiscal, financeiro e de contratações para enfrentamento da pandemia apenas para aquele ano.

Neste artigo, a partir da análise empírica dos dados administrativos do Auxílio Emergencial em 2020 e do Cadastro Único no nível municipal por meio de regressão linear com controles socioeconômicos, investigam-se outros elementos importantes para balizar propostas de reformulação de políticas de transferência de renda no Brasil que têm sido

\footnotetext{
${ }^{10}$ Chamada oficialmente de "Auxílio Emergencial Residual".

"Em média, US\$ 48 mensais.
} 
negligenciados nas discussões correntes. Primeiro, a análise empreendida mostra que a distribuição dos três grupos beneficiários da RBE em cada município é bastante heterogênea e está relacionada com fatores socioeconômicos. Assim, alterações no desenho do PBF impactam de forma diferenciada os municípios brasileiros, tanto do ponto de vista do seu papel no cadastramento e controle das condicionalidades, quanto dos benefícios econômicos que auferem. Dada a importância federativa para a política de assistência no Brasil, é preciso levar isso em consideração nas propostas de alteração de elementos do PBF.

Segundo, sublinha-se que o cadastro do aplicativo da CEF não contém diversas informações presentes no Cadúnico centrais para o desenho e avaliação de políticas sociais efetivas para a superação de vulnerabilidades, que são importantes de serem mantidas no arcabouço institucional da proteção social brasileira. A partir de outros estudos e de dados próprios, ressalta-se que o Cadúnico vinha sofrendo defasagem nos anos recentes, revelando processos de policy drift $^{12}$ da política social, mesmo com o aumento da pobreza neste período ${ }^{13}$. Mais do que isso, mostra-se que esta desidratação ajuda a explicar o nível de inclusão de "invisíveis" pela renda emergencial.

Assim, este artigo dá subsídios para discussões acerca do futuro de uma das mais famosas políticas de transferência do mundo. Mostra que, ainda que a cobertura do Auxílio Emergencial tenha colocado na pauta a necessidade de inclusão de novos grupos, parte deles já estaria presente caso o instrumento tradicional do Cadúnico não tivesse passado por enxugamento no período recente. Ao mesmo tempo, o cadastramento digital durante a pandemia mostrou potencialidades que podem ser permanentemente adotadas, mas é importante retomar o detalhamento de informações do Cadúnico e não abrir mão dos profissionais do SUAS na

\footnotetext{
${ }^{12} \mathrm{O}$ conceito de policy drift se refere à compressão passiva ou ativa de políticas públicas devido à ausência de atualização de seus parâmetros ou enxugamento de seus mecanismos de funcionamento (GALVIN; HACKER, 2020)

${ }^{13}$ Explicado em parte pela Emenda Constitucional de 2016 que estabeleceu o chamado "teto de gastos", determinando que as despesas primárias do governo federal não devem ultrapassar a inflação do ano anterior.
} 
busca ativa de potenciais beneficiários e no auxílio às pessoas com dificuldades de acesso e manuseio das ferramentas digitais. Ademais, este artigo reforça a necessidade da pactuação federativa na formulação e desenho das políticas de transferência, dados os ganhos que a articulação com o SUAS e demais políticas sociais, principalmente no nível local, tiveram nos últimos anos.

O Brasil foi o país que mais se destacou na América Latina ao estabelecer um benefício elevado e abrangente em meio à crise pandêmica, segundo Blofield, Giambruno e Filgueira (2020). O estudo de caso intensivo feito neste artigo indica questões que também se aplicam às demais nações da região, de modo que nas conclusões são realizadas algumas considerações comparativas com os demais países latino-americanos, ressaltando a importância de cadastros expandidos, mas atualizados e abrangentes, para a melhoria das políticas sociais na região.

Além desta introdução e da conclusão, o artigo apresenta o processo de formulação, implementação e as questões colocadas na agenda pelo Auxílio Emergencial. Depois, remete à importância das dimensões federativas e informacionais da política de transferência, e então é apresentada a análise empírica.

\section{A RBE, os problemas na sua implementação e o os desafios futuros}

Em meados de março de 2020, quando se iniciavam as crises geradas pela pandemia de Covid-19, o ministro da Economia Paulo Guedes manifestou a intenção de conceder um auxílio emergencial mensal no valor de US\$ 40 para trabalhadores informais não contemplados pelo PBF, mas inscritos no Cadúnico. No entanto, a Câmara dos Deputados se antecipou e pautou a discussão com um projeto que propunha valor mais elevado e inovava ao abarcar os beneficiários do PBF e pessoas não 
inscritas no Cadúnico que tiveram perda de renda no período recente (SIMONI JR.; GUICHENEY; OLIVEIRA, 2021).

Antecipando que o auxílio seria aprovado com relativa facilidade, o líder do governo na Câmara ampliou o auxílio para US \$230, em alguns casos. Esta proposta foi aprovada por meio de votação simbólica tanto na Câmara quanto no Senado. Tornaram-se elegíveis indivíduos com renda mensal per capita de até 1/2 salário-mínimo ou renda familiar total de até três salários-mínimos, maiores de $18 \operatorname{anos}^{14}$, sem emprego formal ativo, não titulares de benefício previdenciário, assistencial ou de transferência de renda (salvo o PBF), dentre outros critérios mais específicos.

Em 2020, receberam ao menos uma parcela do Auxílio Emergencial 68 milhões de pessoas, sendo quase 19,5 milhões oriundos do PBF, 10,5 milhões de pessoas constantes no Cadúnico, mas não beneficiárias do PBF, e 38 milhões de pessoas que precisaram se cadastrar pelo aplicativo da CEF. Dadas as composições domiciliares, o benefício médio chegou a cerca de US\$175, mais de quatro vezes a transferência média do PBF no período pré-pandêmico.

No entanto, de início o Auxílio Emergencial apresentou notáveis dificuldades de implementação (BARTHOLO et al., 2020). O grande problema incidiu no cadastramento do grupo de fora do Cadúnico e na inserção bancária das pessoas sem conta corrente. Para regulamentar o benefício, o Executivo determinou que todos os membros da família de pleiteantes deveriam ter inscrição no Cadastro de Pessoas Físicas (CPF) regularizada e concentrou a operacionalização da RBE em apenas uma rede bancária, a CEF, a mesma que maneja os benefícios do PBF. Durante as deliberações legislativas, a liderança do governo rejeitou uma emenda que permitiria que os Centros de Referência de Assistência Social (CRAS) principal equipamento do SUAS, com alta capilaridade geográfica e expertise com a inserção da população mais vulnerável à rede de proteção social -auxiliassem a implementação do benefício (SIMONI JR.; GUICHENEY; OLIVEIRA, 2021). Além de causar filas e aglomerações para

\footnotetext{
${ }^{14}$ A idade seria posteriormente flexibilizada no caso de mães monoparentais.
} 
saque da RBE e regulamentação de documentos, estas medidas dificultaram o acesso inicial particularmente para os mais vulneráveis, que possuem dificuldade com documentação, de acesso à internet e capacidade para realização de operações bancárias, notadamente em meio digital (REDE DE PESQUISA SOLIDÁRIA, 2020).

Em suma, o Auxílio Emergencial teve enorme impacto no combate às consequências socioeconômicas da pandemia, mas sua implementação passou ao largo das capacidades do SUAS ${ }^{15}$, inclusive daquelas presentes no nível municipal, causando problemas no momento inicial de implementação. Difícil mensurar o impacto negativo desses percalços nas condições de vida dos elegíveis, mas não é descabido supor que foi significativo tendo em vista o choque imediato que a pandemia acarretou nas condições de vida da população.

Dado o caráter transitório da RBE, diversos atores colocaram no centro da agenda brasileira a importância de se fortalecer ou reformular o PBF, ou até de se criar outro programa social permanente, mais abrangente e/ou com benefícios mais elevados. Na verdade, desde 2019 o governo Bolsonaro dava indicações de que pretendia substituir o PBF por um programa de sua autoria ${ }^{16}$, assunto que voltou na pauta do governo no final de 2020 e adentrou 2021 sem uma definição concreta17. Concomitantemente, um amplo conjunto de atores da sociedade civil, que já tivera influência no momento de deliberação legislativa do Auxílio Emergencial (OLIVEIRA, 2021), ganhou relevância em 2020 demandando a instituição de uma renda básica universal. Uma frente parlamentar foi formada composta por quase metade do Congresso, de praticamente todos os partidos, mas com pouco avanço efetivo ${ }^{18}$.

\footnotetext{
${ }^{15}$ Como notaram Pinheiro et al., (2020: 13), outras demonstrações de desarticulação com a estrutura do SUAS foram a parceria que o Ministério da Cidadania estabeleceu com os Correios para auxílio no cadastramento no aplicativo da CEF, ignorando as assistentes sociais, e a exclusão da Secretaria Nacional responsável pela Assistência Social do Comitê Gestor do Auxílio Emergencial.

${ }^{16}$ Disponível em: https://tinyurl.com/y6duetsq. Acesso em: 5 set. 2021

${ }_{17}$ Disponível em: https://bbc.in/3p2AF90. Acesso em: 5 set. 2021.

${ }^{18}$ Cabe notar que o arcabouço legislativo brasileiro já prevê a implementação da renda básica desde 2003. Esta lei, no entanto, nunca foi posta em prática.
} 
Não faltam estudos e propostas de novos programas formuladas por especialistas (PAIVA; BARTHOLO; SOUZA , 2021; BOTELHO et al., 2020; SOARES, BARTHOLO, OSORIO, 2019). De modo geral, as análises elaboradas ressaltam que uma renda básica universal no Brasil seria ou inviável, dado o altíssimo custo fiscal de transferências efetivas, ou irrelevante, caso factível do ponto de vista orçamentário. De modo geral, as propostas alternativas oferecidas, pautam-se pelos seguintes critérios: (i) unificação de benefícios correntes $^{19}$, de modo a aumentar a progressividade, via aumento na cobertura e no valor do benefício, em relação ao cenário atual, mas sem incorrer em aumento de gastos; (ii) o estabelecimento de benefícios sem cortes abruptos após elevação da renda das famílias ${ }^{20}$; e (iii) um componente de benefício universal, de modo geral destinado às crianças. Do ponto de vista de seu desenho, as propostas buscam: (iv) mecanismos simples e implementação gradual, a partir dos arranjos existentes; (v) flexibilidade institucional às mudanças demográficas e situações de calamidade; e (vi) a utilização das oportunidades tecnológicas trazidas pela experiência do Auxílio Emergencial, tanto do ponto de vista do sistema de pagamentos, quanto do cadastramento e atualização.

Este artigo chama atenção para a centralidade desse último ponto. Ressaltou-se acima que a RBE não teve articulação com o sistema de Assistência Social, o que prejudicou sua implementação inicial no grupo majoritário que não se encontrava no Cadúnico. Mesmo neste sistema, o Ministério da Cidadania permitiu a coleta dos dados para inclusão e atualização cadastral por telefone ou por meio eletrônico durante a situação de emergência ${ }^{21}$, o que foi necessário em um contexto que exigia distanciamento social. No entanto, logo no começo de 2021 o governo começou a estudar um processo de utilização permanente e exclusiva do meio digital nos mecanismos de cadastramento no Cadúnico,

\footnotetext{
${ }^{19}$ Principalmente o PBF, Abono Salarial, Salário-Família, Seguro-Defeso e a dedução por criança dependente no Imposto de Renda.

${ }^{20} \mathrm{As}$ medidas (i) e (ii) permitem também lidar com o problema da volatilidade da renda que atinge especialmente as pessoas mais pobres no Brasil, dada sua inserção precária no mercado de trabalho (Soares, 2009).

${ }^{21}$ Disponível em: https://bit.ly/3clZIVm. Acesso em: 5 set. 2021.
} 
contornando as estruturas locais do SUAS, o que gerou críticas na comunidade desta política pública22.

Há facilidades e agilidades proporcionadas pela digitalização, mas este meio não pode substituir os processos presenciais, sob pena de dificultar o acesso justamente dos grupos mais vulneráveis. Além disso, conforme se verá na próxima seção, algumas propostas correntes desconsideram as potencialidades do questionário detalhado do Cadúnico na formulação de políticas sociais, que apenas se efetivam por meio do acompanhamento oferecido por profissionais da assistência social às famílias, serviço este que faz parte de um arranjo sistêmico de relações intergovernamentais nos quais os municípios são os atores mais essenciais.

\section{A dimensão federativa e informacional da política de transferência}

Ainda que o governo federal seja o responsável pela formulação do PBF, Soares e Sátyro (2009) e Lício, Mesquita e Curralero (2011) ressaltam que este Programa abrange importantes dimensões federativas, notadamente no acompanhamento das condicionalidades e na articulação de programas complementares, ações que visam permitir às famílias o desenvolvimento de capacidades geradoras de renda.

Desde 2005, portarias do então Ministério do Desenvolvimento Social (MDS) -hoje, Ministério da Cidadania- iniciaram o estabelecimento de mecanismos para repasse de recursos do governo federal para aprimoramento da gestão do PBF em níveis subnacionais, o que desembocaria na formulação do Índice de Gestão Descentralizada Municipal (IGD-M) - além da versão estadual (ARAÚJO et. al., 2018; BICHIR, 2011). Este e outros instrumentos foram essenciais para a disseminação de capacidades estatais locais na área de assistência.

\footnotetext{
22Disponível em: https://bit.ly/3vDt83H. Acesso em: 5 set. 2021.
} 
O Cadúnico foi instituído em 2001, antes mesmo do PBF. Desde então, passou por diversas atualizações e aprimoramentos por meio de consultas a vários atores sociais e instituições de pesquisa (DIREITO et al., 2018: 104). A prioridade no cadastramento é de famílias com renda mensal igual ou inferior a meio salário mínimo per capita, ou renda familiar mensal de até três salários mínimos ${ }^{23}$. A inscrição pode ser realizada pelo deslocamento do responsável pela família até o local público que realiza este serviço, normalmente o CRAS, pela visita do entrevistador à residência da família, ou mesmo por meio de uma ação de mobilização social. Diretivas antigas do MDS recomendavam que a coleta de dados fosse feita por meio de visitas domiciliares para que fosse possível verificar, in loco, as condições socioeconômicas ${ }^{24}$, bem como reforçavam a estratégia da busca ativa, importante em contextos de difícil mobilidade e acesso ao poder público de pessoas vulneráveis (DIREITO et al., 2016: 3).

As principais informações presentes no Cadúnico são: características do domicílio (número de cômodos, tipo de construção, tratamento da água, esgoto e lixo), sua composição familiar (número de membros, existência de gestantes, idosos, mães amamentando, deficientes físicos); a qualificação escolar, profissional, a situação no mercado de trabalho e a identificação e documentação civil dos membros da família; rendimentos e as despesas familiares (aluguel, transporte, alimentação e outros), e a vinculação a programas e serviços públicos. Destacam-se também os blocos referentes a grupos específicos, notadamente indígenas, quilombolas e a população de rua.

As normativas recomendam que sempre que houver alguma mudança nas características da família, especialmente no que se refere à sua composição e renda, os registros devem ser atualizados. Mesmo sem

\footnotetext{
${ }^{23} \mathrm{As}$ famílias que tenham renda superior a estes patamares podem ser cadastradas, desde que a inclusão esteja vinculada à seleção ou ao acompanhamento de programas sociais implementados em nível federal, estadual ou municipal.

${ }^{24}$ Disponível em: https://bit.ly/3yQSv4c. Acesso em: 5 set. 2021.
} 
alterações nos dados, beneficiários do PBF devem ratificar as informações prestadas no período máximo de dois anos, sob risco de penalidades ${ }^{25}$.

O amplo diagnóstico socioeconômico das famílias permite sua utilização em diversas políticas públicas, pelos três níveis de governo. Direito et al. (2018) identificaram cerca de 30 programas federais que utilizam as informações do Cadúnico para seleção de beneficiários e para fins de monitoramento ${ }^{26}$. Algumas dessas políticas têm arranjos intergovernamentais importantes, o que reforça essa dimensão do Cadúnico. Como afirmam Paes de Barros, Carvalho e Mendonça (2009: 11) o "uso do Cadúnico pelos diversos programas sociais não só reduz custos e facilita a integração, como também estimula a própria melhoria das informações nele contidas".

O cadastro digital criado no momento emergencial pela CEF para a inclusão de pessoas fora do Cadúnico para recebimento da RBE é consideravelmente diferente do instrumento relatado acima. Primeiro, trata-se de autocadastramento, sem auxílio de profissionais da assistência. Segundo, contém um leque de informações substancialmente mais simples, a saber: número do CPF; data de nascimento; nome da mãe; dados de quanto o pleiteante costumava ganhar por mês antes da crise do coronavírus; atividade profissional; nome, número do CPF, data de nascimento e grau de parentesco de cada um dos demais moradores do domicílio; e a cidade e o estado de residência.

Dessa forma, a inclusão nos cadastros governamentais dos outrora "invisíveis" é bastante precária do ponto de vista informacional, não permitindo, diferentemente do Cadúnico, subsídios para formulação e avaliação de políticas públicas destinadas a combater as vulnerabilidades deste grupo social. Evidentemente, o processo de cadastramento digital, que exige também um questionário reduzido, foi necessário no contexto pandêmico, e as possibilidades que este instrumento trouxe devem ser

\footnotetext{
${ }^{25} \mathrm{~A}$ atualização dos dados é essencial ao ponto das diretivas do Ministério prescreverem que sua responsabilidade não é somente das famílias, mas também dos gestores municipais do Cadúnico.

${ }^{26}$ As autoras ressaltam que outros tantos programas estaduais e municipais não mapeados também utilizam o Cadúnico.
} 
consideradas no momento posterior de retorno às atividades presenciais. No entanto, isso não deve vir à custa da perda informacional possibilitada pelo Cadúnico, e sem desconsiderar as dificuldades que grande parte da população vulnerável tem na esfera digital (BARTHOLO et al., 2020: 14).

Mais do que isso. A exclusão de parte da população dos cadastros governamentais se deve a um processo recente de desidratação do orçamento da Assistência Social. Como mostram Peres e Santos (2020) e Barbosa, Ferreira de Souza e Soares (2020), o contingente de beneficiários e os gastos com o PBF diminuíram a partir de 2014. Contraditoriamente, isso se deu em um período de crise econômica e aumento da pobreza e da desigualdade. A Rede de Pesquisa Solidária (2020) mostrou que o Cadúnico seguiu uma trajetória semelhante: o total de pessoas com registro atualizado caiu de mais de 85 milhões em 2014 para menos de 75 milhões em 202027. Ademais, a estimativa de público do Cadúnico e o valor do IGD-M não são atualizados desde 2011.

Como é mostrado na análise empírica realizada abaixo, este processo de policy drift ocorreu de forma desigual pelos municípios e teve impacto nas configurações locais dos grupos beneficiários do Auxílio Emergencial.

\section{Análise empírica - determinantes dos grupos de beneficiários por município}

A fonte de dados analisada consiste nos cadastros administrativos do Ministério da Cidadania e nas informações do Instituto Brasileiro de Geografia e Estatística (IBGE) ${ }^{28}$. Para cada município, foi calculada a percentagem de beneficiários do Auxílio Emergencial em 2020 que se distribuiu em cada grupo.

Para verificar a distribuição dos grupos beneficiários por características socioeconômicas das localidades, elaborou-se regressões

\footnotetext{
${ }^{27}$ Cabe notar que os serviços de assistência auxiliam também a população vulnerável a providenciar documentos, como o CPF, que causou problemas na implementação do Auxílio Emergencial.

${ }^{28}$ Disponivel em: https://aplicacoes.mds.gov.br/sagi/vis/data3/index.php?g=2\&ag=m e em: http://www.atlasbrasil.org.br/, respectivamente. Acesso em: 5 set. 2021.
} 
lineares utilizando as seguintes variáveis explicativas: a porcentagem de pobres; O índice GINI de desigualdade de renda (ambos mensurados no Censo de 2010); o PIB per capita de 2018 (em versão logarítmica), a região e o porte de cada município, segundo a classificação do Censo SUAS a partir do Censo de 2010. Por fim, de modo a analisar se e como o tamanho proporcional de cada grupo se relaciona com o definhamento do SUAS no período recente, calculou-se a diferença proporcional entre o número de pessoas inscritas no Cadastro Único em fevereiro de 2020, no momento da chegada da pandemia de Covid-19 no Brasil, em relação à fevereiro de 2014, período de menor proporção de pessoas pobres no Brasil e às vésperas da crise econômica e fiscal que assolaria o país pelos anos seguintes. 
Abaixo se encontra a tabela 1 com a distribuição dos dados:

Tabela 1 - Estatísticas descritivas

\begin{tabular}{lcccc}
\hline \multicolumn{5}{c}{ Variáveis contínuas } \\
\hline & Média & Desvio-padrão & Mínimo & Máximo \\
Beneficiários grupo: PBF & 36,61 & 20,84 & 0,78 & 84,89 \\
Beneficiários grupo: Cadúnico & 18,26 & 6,69 & 0,97 & 50,25 \\
Beneficiários grupo: Extracad & 45,11 & 19,79 & 6,89 & 96,61 \\
$\Delta$ Cadúnico 2020-2014 & $-17,44$ & 19,6 & $-82,96$ & 374,3 \\
\% Pobres & 23,2 & 17,91 & 0 & 78,59 \\
GINI & 0,4943 & 0,066 & 0,28 & 0,8 \\
(In) PIB per capita & 9,79 & 0,69 & 8,47 & 13,27 \\
\hline
\end{tabular}

\begin{tabular}{|c|c|}
\hline \multicolumn{2}{|c|}{ Variáveis categóricas } \\
\hline Região & $\mathrm{N}$ \\
\hline Região Centro-Oeste & 466 \\
\hline Região Nordeste & 1794 \\
\hline Região Sudeste & 1668 \\
\hline Região Sul & 1188 \\
\hline Região Norte & 449 \\
\hline Porte & $\mathrm{N}$ \\
\hline Pequeno I & 3858 \\
\hline Pequeno II & 1042 \\
\hline Médio & 325 \\
\hline Grande & 266 \\
\hline
\end{tabular}

Fonte: elaboração própria a partir do Ministério da Cidadania e IBGE - 2021

A informação que mais salta os olhos é a diminuição na média municipal do número de pessoas inscritas no Cadastro Único entre fevereiro 2014 e 2020: ao mesmo tempo que crescia a pobreza e desigualdade, houve queda de $17 \%$ no número de pessoas incluídas no principal sistema de informação de políticas sociais voltadas para população vulnerável. Cabe notar que o desvio-padrão dessa medida é elevado, maior do que a média, o que indica grande variação na forma como esse processo se deu entre as localidades. Em verdade, em 666 municípios houve aumento no número de cadastramentos, ao mesmo tempo que em 193 cidades houve queda acima de 50\%. 
Os mapas abaixo mostram a distribuição geográfica dos três grupos beneficiários do Auxílio Emergencial. Fica evidente a similaridade na proporção municipal entre pessoas que estavam no Cadúnico, mas não beneficiários do PBF, e aquelas que estavam ausentes dos cadastros governamentais. Estes grupos estão mais presentes, em termos relativos, no Sudeste, Centro-Oeste e Sul do Brasil. O grupo do PBF, por sua vez, é mais proeminente no Norte e Nordeste.

Mapa 1 - Distribuição geográfica da composição de beneficiários da RBE

Grupo Cadúnico

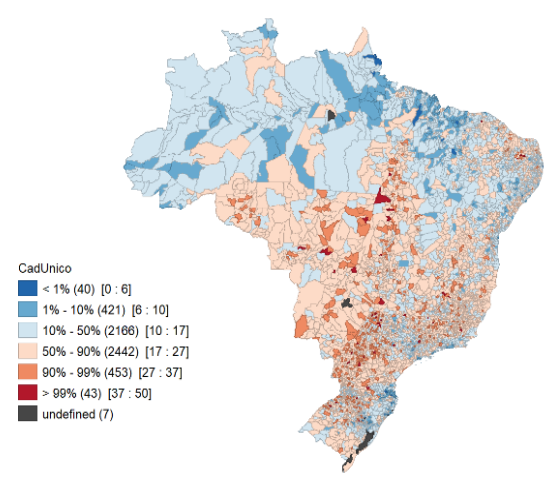

Grupo Extracad

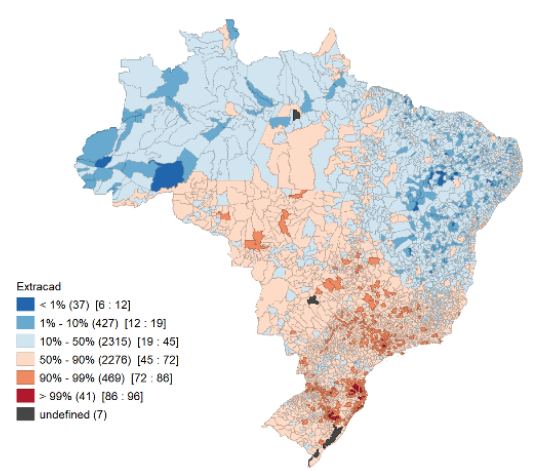

Grupo PBF

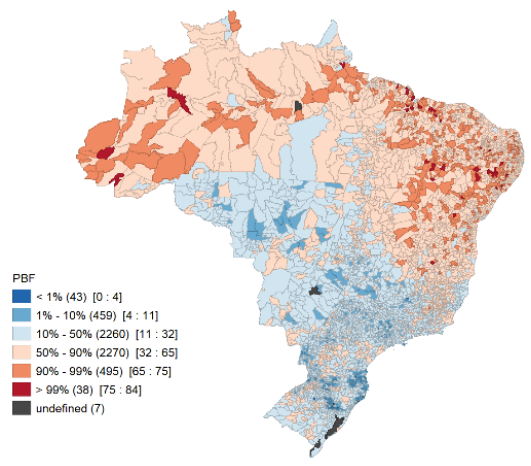

Fonte: elaboração própria a partir do Ministério da Cidadania e IBGE (2021)

Por fim, a tabela 2 abaixo apresenta os resultados de seis modelos de regressão linear ${ }^{29}$. Para cada grupo beneficiário, estimou-se um modelo incluindo apenas variáveis socioeconômicas e geográficas, e outro adicionando a medida da variação de inscritos no Cadúnico. Dessa forma, é possível verificar em que medida o policy drift do SUAS nos últimos anos ajuda a explicar o perfil de beneficiários do Auxílio Emergencial.

\footnotetext{
${ }^{29}$ Foram utilizados erros-padrões robustos. Como as variáveis explicativas são as mesmas em todas as análises, a aplicação de modelos SUR (Seemingly Unrelated Regression), adequados para lidar com a natureza composicional da variável dependente, não altera os resultados.
} 
Tabela 2 - Regressão OLS - Determinantes da composição de beneficiários da RBE - 2020

\begin{tabular}{|c|c|c|c|c|c|c|}
\hline & (1) & (2) & (3) & (4) & (5) & (6) \\
\hline & $\begin{array}{l}\text { Grupo: } \\
\text { PBF }\end{array}$ & $\begin{array}{c}\text { Grupo: } \\
\text { PBF }\end{array}$ & $\begin{array}{l}\text { Grupo: } \\
\text { Cadúnico }\end{array}$ & $\begin{array}{c}\text { Grupo: } \\
\text { CadÚnico }\end{array}$ & $\begin{array}{l}\text { Grupo: } \\
\text { Extracad }\end{array}$ & $\begin{array}{l}\text { Grupo: } \\
\text { Extracad }\end{array}$ \\
\hline \multirow[t]{2}{*}{$\triangle$ CadÚnico 2020-2014 } & & $0.0593^{* * *}$ & & $0.0635^{* * *}$ & & $-0.123^{* *}$ \\
\hline & & (0.0103) & & (0.00732) & & $(0.0445)$ \\
\hline \multirow[t]{2}{*}{$\%$ Pobres } & $0.851^{* * *}$ & $0.837^{* * *}$ & $-0.163^{* * *}$ & $-0.178^{* * *}$ & $-0.688^{* * *}$ & $-0.659^{* * *}$ \\
\hline & $(0.0140)$ & $(0.0141)$ & (0.0103) & $(0.0104)$ & (0.0164) & (0.103) \\
\hline \multirow[t]{2}{*}{ GINI } & $-11.08^{* * *}$ & $-9.782^{* * *}$ & 2.508 & $3.902^{* *}$ & $8.574^{* * *}$ & 5.880 \\
\hline & $(2.215)$ & $(2.215)$ & (1.836) & (1.825) & $(2.742)$ & (10.01) \\
\hline (Ln) PIB per capita & $\begin{array}{l}-3.046^{* * *} \\
(0.220)\end{array}$ & $\begin{array}{l}-3.176^{* * *} \\
(0.218)\end{array}$ & $\begin{array}{c}-0.459^{* *} \\
(0.195)\end{array}$ & $\begin{array}{c}-0.599^{* * *} \\
(0.190)\end{array}$ & $\begin{array}{l}3.506^{* * *} \\
(0.287)\end{array}$ & $\begin{array}{l}3.775^{* * *} \\
(0.560)\end{array}$ \\
\hline \multirow[t]{2}{*}{ Nordeste } & $7.348^{* * *}$ & $7.850^{* * *}$ & $-2.063^{* * *}$ & $-1.525^{* * *}$ & $-5.284^{* * *}$ & $-6.325^{* * *}$ \\
\hline & $(0.424)$ & $(0.416)$ & $(0.302)$ & (0.326) & $(0.417)$ & (2.133) \\
\hline \multirow[t]{2}{*}{ Sudeste } & 0.869 & $1.553^{* * *}$ & $-1.876^{* * *}$ & $-1.143^{* * *}$ & $1.008^{*}$ & -0.410 \\
\hline & $(0.529)$ & $(0.520)$ & $(0.386)$ & $(0.405)$ & (0.557) & $(4.016)$ \\
\hline \multirow[t]{2}{*}{ Sul } & $-2.694^{* * *}$ & $-1.473^{* *}$ & $-3.137^{* * *}$ & $-1.829^{* * *}$ & $5.831^{* * *}$ & 3.302 \\
\hline & $(0.570)$ & $(0.596)$ & $(0.440)$ & $(0.474)$ & $(0.630)$ & $(4.583)$ \\
\hline \multirow[t]{2}{*}{ Centro-Oeste } & 0.122 & 0.591 & 0.0242 & 0.526 & -0.146 & -1.117 \\
\hline & $(0.609)$ & (0.593) & $(0.448)$ & (0.459) & (0.632) & (3.482) \\
\hline \multirow[t]{2}{*}{ Pequeno II } & $-2.439^{* * *}$ & $-2.571^{* * *}$ & $-3.494^{* * *}$ & $-3.636^{* * *}$ & $5.933^{* * *}$ & $6.206^{* * *}$ \\
\hline & $(0.244)$ & $(0.240)$ & (0.186) & (0.187) & (0.288) & (0.704) \\
\hline \multirow[t]{2}{*}{ Médio } & $-3.452^{* * *}$ & $-3.639^{* * *}$ & $-4.538^{* * *}$ & $-4.738^{* * *}$ & $7.990^{* * *}$ & $8.377^{* * *}$ \\
\hline & (0.383) & (0.372) & $(0.312)$ & $(0.312)$ & (0.467) & (0.952) \\
\hline \multirow[t]{2}{*}{ Grande } & $-4.375^{* * *}$ & $-4.979^{* * *}$ & $-6.661^{* * *}$ & $-7.309^{* * *}$ & $11.04^{* * *}$ & $12.29^{* * *}$ \\
\hline & (0.363) & $(0.367)$ & $(0.355)$ & $(0.362)$ & (0.479) & (0.930) \\
\hline \multirow[t]{2}{*}{ Metrópole } & $-2.787^{* *}$ & $-3.278^{* * *}$ & $-9.105^{* * *}$ & $-9.631^{* * *}$ & $11.89^{* * *}$ & $12.91^{* * *}$ \\
\hline & (1.100) & (1.021) & (1.111) & (0.989) & (1.353) & (1.775) \\
\hline \multirow[t]{2}{*}{ Constante } & $51.02^{* * *}$ & $52.40^{* * *}$ & $28.54^{* * *}$ & $30.02^{* * *}$ & $20.44^{* * *}$ & 17.58 \\
\hline & $(2.443)$ & $(2.438)$ & $(2.045)$ & (2.026) & (3.089) & (12.10) \\
\hline$N$ & 5508 & 5508 & 5508 & 5508 & 5508 & 5508 \\
\hline $\operatorname{adj} . R^{2}$ & 0.883 & 0.885 & 0.215 & 0.244 & 0.808 & 0.820 \\
\hline
\end{tabular}

Erros-padrões robustos em parênteses

$$
p<0.1,{ }^{* *} p<0.05,{ }^{* * *} p<0.01
$$

Fonte: elaboração própria a partir do Ministério da Cidadania e IBGE - 2021 
Em todos os modelos, quanto maior a porcentagem de pobres e menor o PIB per capita, maior o peso do grupo PBF entre os beneficiários da Renda Emergencial, e menor o peso tanto do grupo inscrito no Cadúnico, mas fora do PBF, quanto do contingente de informais outrora classificados como "invisíveis". Perfil semelhante apresentam os municípios localizados no Nordeste, em comparação com municípios da região Norte (grupo de referência). Já os menores municípios, o grupo Pequeno I, que serve de baseline na regressão, tem maior percentual dos dois grupos que já estavam cadastrados: em todos os demais portes, o coeficiente do grupo "PBF" e "Cadúnico" tem coeficiente negativo e o grupo "Extracad" tem coeficiente positivo.

Esses resultados são esperados tendo em vista as desigualdades socioeconômicas e espaciais brasileiras. No entanto, as estimativas também mostram a importância da trajetória recente do funcionamento do SUAS: a variação de inscritos no Cadúnico entre 2014 e 2020 ajuda a entender a composição de beneficiários do Auxílio Emergencial, já que tem coeficiente estatisticamente significativo em todos modelos, e, mais do que isso, altera algumas das relações entre as variáveis socioeconômicas e geográficas.

Nas localidades nas quais se aumentou o contingente de inscritos no Cadúnico nesse período, maior foi o grupo "PBF" (modelo 2) e "Cadúnico" (modelo 4) na composição da RBE, mas, principalmente, menor o peso do grupo que estava fora dos cadastros do governo (modelo 6). Levando em consideração este último, para cada aumento de um ponto percentual na defasagem do cadastro, da forma como aqui foi medida, aumenta-se em média 0,12 pontos percentuais a proporção municipal relativa de pessoas incluídas exclusivamente para o Auxílio Emergencial.

Em outras palavras, a desidratação do SUAS nos últimos anos implicou no afastamento da política social assistencial de um grupo vulnerável ou potencialmente vulnerável da população brasileira. Além 
disso, a inclusão desta variável (" $\triangle$ Cadúnico 2020-2014") muda a significância do GINI e de algumas regiões em alguns modelos, indicando que a desidratação da implementação do SUAS não foi homogeneamente distribuída. Por exemplo, o grupo "PBF" se torna mais proeminente nos municípios do Sudeste na comparação com municípios do Norte (modelo 2), ao passo que o tamanho do grupo "Extracad" perde diferenciação entre as duas regiões (modelo 6). O Sudeste e o Sul são as regiões com maior média municipal de queda do número de famílias inscritas no Cadúnico no período analisado, -18,92\% e -28,73\%, respectivamente.

Dessa forma, as evidências reforçam os pontos levantados neste artigo. Alterações no desenho das políticas de transferência tem impacto diferenciado entre os municípios, entes responsáveis pelo cadastramento e controle das condicionalidades, dado o peso heterogêneo de cada grupo entre as localidades (e a importância da renda transferida na economia local, aspecto aqui não diretamente abordado). Além disso, a própria incorporação efetiva de novos grupos ao sistema de proteção social brasileiro é prejudicada pela desidratação pela qual passou o SUAS nos últimos anos, problema que não é totalmente resolvido pelos mecanismos emergenciais adotados, dado que mais simples e precários.

\section{Conclusão}

A pandemia da Covid-19 exigiu ações rápidas, complexas e conflitivas dos governos de modo a minimizar as crises sanitárias, econômicas e sociais que acarretou. Analisando países da América Latina, Blofield, Giambruno e Filgueira (2020) ressaltam que no Brasil foi instituída a política de transferência de renda para vulneráveis de maior abrangência e efetividade. Neste artigo, realizou-se um estudo intensivo desse caso, relatando-se o processo de formulação e implementação do Auxílio Emergencial, e debateu-se com os desafios em aberto que as características deste benefício trouxeram para o futuro das políticas 
assistenciais. Para além das propostas vigentes de aumento da cobertura e do valor do benefício, ressaltou-se a importância da articulação federativa e da existência de um cadastro abrangente de informações sociais que permitam a consecução de políticas sociais efetivas.

Problema semelhante se coloca também para os demais países da região. Como mostram Blofield, Giambruno e Filgueira (2020), as respostas na maioria dos casos envolveram reforço dos programas existentes e criação de novas medidas emergenciais de modo a abranger trabalhadores informais até então ausentes dos benefícios governamentais. Em ao menos seis países (Argentina, Bolívia, Chile, Costa Rica, Peru e Uruguai), foram estabelecidos mecanismos nos quais indivíduos poderiam se auto-cadastrar e pleitear o auxílio. Dificuldades semelhantes às aqui relatadas emergiram, principalmente nos casos com menor capacidade estatal, destacando-se o Peru, no qual as transferências para milhões de domicílios só começaram em agosto de 2020. Na Argentina, o número de pleiteantes do Ingreso Familiar de Emergencia superou as expectativas governamentais, e no Chile o processo foi claudicante devido aos conflitos entre o Executivo, mais fiscalista, e o Congresso, que buscava aumentar a cobertura e o dispêndio assistencial.

Em todos esses casos, o desafio futuro consiste em incorporar efetivamente aos sistemas de proteção social os "novos vulneráveis" em contextos de mercados de trabalho profundamente heterogêneos e flexíveis. $O$ estudo aprofundado do caso brasileiro mostrou a importância do funcionamento das estruturas assistenciais vigentes. Ressaltou-se que estava ocorrendo processo de policy drift da rede de proteção social no período recente, a despeito do aumento da pobreza. A desarticulação e o enxugamento das políticas públicas voltadas aos mais pobres começaram nos últimos anos do governo do PT de Dilma Rousseff (2011-2016), e se aprofundaram com a agenda fiscalista de Michel Temer (2016-2018) e de Bolsonaro (2019-). 
As análises estatísticas mostraram que a diminuição da cobertura dos registros no Cadúnico tem relação significativa com a porcentagem de grupos incluídos exclusivamente para receber o Auxílio Emergencial no nível municipal, revelando que a crise da pandemia poderia ter sido combatida com mais rapidez e efetividade caso o SUAS não tivesse passando por processos de desestruturação desde meados da década passada. Cabe notar que além do aspecto do financiamento e da cobertura, Pinheiro et al. (2020) chamam atenção para a desarticulação das instâncias de pactuação federativa e do Conselho Nacional de Assistência Social desde 2019, quando Bolsonaro assumiu.

O Brasil e de modo geral a América Latina avançaram nos últimos anos no combate à desigualdade e pobreza, ainda que já desde meados dos anos de 2010 esta trajetória se mostrasse desgastada. A pandemia da Covid-19 trouxe à tona um cenário ainda fortemente trágico e criou outras crises, exigindo respostas governamentais que em muitos casos ensejaram novas oportunidades de expansão da rede assistencial. Cabe aos políticos, gestores e à sociedade em geral se apropriar do conhecimento produzido e formular propostas que tenham efetividade de curto, médio e longo-prazo nas condições de vida de seus cidadãos.

\section{Referências}

ABRAMO, Luís; CECCHINI, Simone; MORALES, Beatriz. Programas sociales, superación de la pobreza e inclusión laboral: aprendizajes desde América Latina y el Caribe. Santiago: Libros de la CEPAL, $N^{\circ} 155$ (LC/PUB.2019/5-P), 2019.

ARAÚJO, Fábio Resende de et al. Distribuição Espacial do Desempenho do Programa Bolsa Família: Um Estudo à Luz do IGD-M. Dados [online], v. 61, n. 3, pp. 773-806, 2018. doi.org/10.1590/001152582018173. A

BARBOSA, Rogério; FERREIRA DE SOUZA, Pedro; SOARES, Serguei. Desigualdade de renda no Brasil de 2012 a 2019. Blog DADOS, 2020. Disponível em: http://dados.iesp.uerj.br/desigualdade-brasil/. Acesso em: 5 set. 2021. 
BARBOSA, Rogério; PRATES, Ian. Efeitos do desemprego, do Auxílio Emergencial e do Programa Emergencial de Preservação do Emprego e da Renda (MP 936) sobre a renda, a pobreza e a desigualdade durante e depois da pandemia. IPEA - Boletim Mercado de Trabalho - Conjuntura e Análise, n.69, p. 65-79, jul. 2020. Disponível em: http://repositorio.ipea.gov.br/handle/11058/10187. Acesso em: 5 set. 2021.

BARTHOLO, Letícia, et al. As transferências monetárias federais de caráter assistencial em resposta à Covid-19: mudanças e desafios de implementação. Nota Técnica Disoc, n. 72. Brasília: Ipea, 2020. Disponível em: <https://bit.ly/2POvYmQ>. Acesso em: 5 set. 2021.

BASSANI, Ana Taís; FABRIS, Gabriela; SIMONI JR., Sergio. SARS-COV-2: pandemia, negacionismo científico populista de extrema direita e a utilização off label medicamentos. Revista de Políticas Públicas, vol. 25, n.1, 2021. Disponível em: < https://bit.ly/2WSfPjZ>. Acesso em: 5 set. 2021.

BICHIR, Renata. Novos instrumentos de coordenação federativa: reflexões a partir do Programa Bolsa Família. Revista Brasileira de Políticas Públicas e Internacionais, $\quad$ v. 1, n. 1, p.49-78, ago. 2016a. Disponível em: https://periodicos.ufpb.br/index.php/rppi/article/view/28463/15931. Acesso em: 5 set. 2021.

BICHIR, Renata. Novas agendas, novos desafios: reflexões sobre as relações entre transferência de renda e assistência social no Brasil. Novos Estudos Cebrap, v. 35, n. 1, p. 111-135, 2016b. doi.org/10.25091/S0101-3300201600010006.

BICHIR, Renata. Mecanismos federais de coordenação de políticas sociais e capacidades institucionais locais: o caso do Programa Bolsa Família. Rio de Janeiro. Tese (Doutorado em Ciência Política) - Instituto de Estudos Sociais e Políticos, Universidade Estadual do Rio de Janeiro, p. 278, 2011.

BLOFIELD, Merike; GIAMBRUNO, Cecilia; FILGUEIRA, Fernando. Policy expansion in compressed time: assessing the speed, breadth and sufficiency of post-COVID-19 social protection measures in 10 Latin American countries, Social Policy series, No. 235 (LC/TS.2020/112), 2020.

BOTELHO, Vinícius; VELOSO, Fernando; MENDES, Marcos; MACHADO, Anaely; BERÇOT, Ana. Programa de Responsabilidade Social: Diagnóstico e Proposta. Centro de Debates de Políticas Públicas: São Paulo, 2020. Disponível em: https://bit.ly/3wXzQIB. Acesso em: 5 set. 2021.

COSTA, Ecio; FREIRE, Marcelo. Estudo de Avaliação do Programa de Auxílio Emergencial: Uma Análise Sobre Focalização e Eficácia a Nível Municipal. Anais eletrônicos do Encontro da ANPEC, 2020. Disponível em: https://bit.ly/3yMvVIH. Acesso em: 5 set. 2021. 
DENES, Guilherme; KOMATSU, Bruno; MENEZES-FILHO, Naércio. Uma avaliação dos impactos macroeconômicos e sociais de programas de transferência de renda nos municípios brasileiros. Revista Brasileira de Economia, vol. 72, n³, 2018. doi.org/10.5935/0034-7140.20180014.

DIREITO, Denise do Carmo et al. O Cadastro Único como instrumento de articulação de políticas sociais. Working Paper - Centro Internacional de Políticas para o Crescimento Inclusivo, 2016. Disponível em: https://bit.ly/3BL9cic. Acesso em: 5 set. 2021.

DIREITO, Denise do Carmo et al. As possibilidades e os limites do Cadastro único como mecanismo de coordenação federativa e de intersetorialidade de políticas públicas. In: Ximenes, Daniel de Aquino (org.) Implementação de políticas públicas: questões sistêmicas, federativas e intersetoriais, Brasília: Enap, 2018.

GALVIN, Daniel; HACKER, Jacob. The Political Effects of Policy Drift: Policy Stalemate and American Political Development". Studies in American $\begin{array}{llll}\text { Political } \quad \text { Development, } & \text { 34(2), }\end{array}$ doi.org/10.1017/S0898588X2000005X.

IPEA (INSTITUTO DE PESQUISA ECONÔMICA APLICADA). Assistência Social - Políticas sociais: acompanhamento e análise. Brasília: IPEA, n. 26, 2021. Disponível em: https://bit.ly/3n6sMkQ. Acesso em: 5 set. 2021.

LÍCIO, Elaine Cristina; MESQUITA, Camile Sahb; CURRALERO, Claudia Regina Baddini. Desafios para a coordenação intergovernamental do Programa Bolsa Família. Revista de Administração de Empresas [online], v. 51, n. 5, pp. 458-470, 2011. doi.org/10.1590/S0034-75902011000500004.

OLIVEIRA, Vitor. Legislativo e sociedade. In: SANTOS, Fabiano (ed.), Congresso Remoto: A experiência legislativa brasileira em tempos de pandemia. Rio de Janeiro: EdUERJ, 2021.

PAIVA, Luis Henrique; FALCÃO, Tiago; BARTHOLO, Letícia. Do Bolsa Família ao Brasil Sem Miséria: um resumo do percurso brasileiro recente na busca da superação da pobreza extrema. In: CAMPELLO, Tereza; NERI, Marcelo Côrtes. (Eds.). Programa Bolsa Família: uma década de inclusão e cidadania. Brasília: IPEA, p. 25-46, 2013.

PAIVA, Luis Henrique; BARTHOLO, Leticia; SOUZA, Pedro H. G. Ferreira; ORAIR, Rodrigo Octávio. Reformulação das Transferências de Renda no Brasil: Simulações e Desafios. Texto para Discussão - Publicação Preliminar. IPEA, Edição 1, 2021. Disponível em: https://bit.ly/3tgkx6P. Acesso em: 5 set. 2021.

PAES DE BARROS, Ricardo; CARVALHO, Mirela de; MENDONÇA, Rosane. Sobre as Utilidades do Cadastro Único. Texto para Discussão, n. 1414, Ipea, 2009. Disponível em: https://bit.ly/38NAjMM. Acesso em: 5 set. 2021. 
PERES, Ursula; SANTOS, Fábio. Gasto Público e Desigualdade Social: O orçamento do governo federal brasileiro entre 1995 e 2016 . Rev. Bras. Ci. Soc, vol.35, n.103, 2020. doi.org/10.1590/3510307/2020.

PINHEIRO, Maria Brito; PAIVA Andrea Barreto de; LíCIO, Elaine Cristina; NATALINO, Marco; BARTHOLO, Letícia. O financiamento federal dos serviços socioassistenciais em resposta à Covid-19. Nota Técnica, n. 80. Brasília, Ipea: 2020. Disponível em: https://bit.ly/38Jbnq4. Acesso em: 5 set. 2021.

RASELLA, Davide et al. Effect of a conditional cash transfer programme on childhood mortality: a nationwide analysis of Brazilian municipalities. The Lancet, 382(9886): 57-64, 2013. doi.org/10.1016/S0140-6736(13)60715-1.

REDE de PESQUISA SOLIDÁRIA. Covid-19: Políticas Públicas e as Respostas da Sociedade. Nota Técnica No. 5 - Dificuldades com aplicativo e não uso da rede de proteção atual limitam acesso ao auxílio de emergência, 2020. Disponível em: https://tinyurl.com/yykq5nfe. Acesso em: 5 set. 2021.

SILVA, Maria Ozanira da Silva; YASBEK, Maria Carmelita; DI GIOVANNI, Geraldo. A política social brasileira no século XXI: a prevalência dos programas de transferência de renda. São Paulo: Ed. Cortez, 2012.

SIMONI JR., Sergio. Efeitos diretos e indiretos do Programa Bolsa Família nas eleições presidenciais brasileiras. Opinião Pública, vol. 27, $\mathrm{n}^{\circ}$ 1, 2021. doi.org/10.1590/1807-01912021271230.

SIMONI JR., Sergio; GUICHENEY, Hellen; OLIVEIRA, João Sacchi. O Congresso e a Renda Emergencial. E-Legis, Edição Especial, p. 164-181, 2021. Disponível

em: http://e-legis.camara.leg.br/cefor/index.php/e-legis/article/view/651. Acesso em: 5 set. 2021.

SOARES, Sergei. Volatilidade de renda e a cobertura do Programa Bolsa Família. Texto para Discussão, n. 1459, Rio de Janeiro: Ipea, 2009. Disponível em: https://bit.ly/3yNug5x. Acesso em: 5 set. 2021.

SOARES, Sergei; BARTHOLO, Letícia; OSÓRIO, Rafael. G. Uma Proposta para Unificação dos Benefícios Sociais de Crianças, Jovens e Adultos Pobres e Vulneráveis. Texto para Discussão, n. 2505, Brasília: Ipea, 2019. Disponível em: https://bit.ly/38Gkcke. Acesso em: 5 set. 2021.

SOARES, Sergei; SÁTYRO, Natália. O Programa Bolsa Família: Desenho Institucional, Impactos e Possibilidades Futuras. Texto para Discussão, n. 1424, Ipea, 2009. Disponível em: https://bit.ly/3jJUodq. Acesso em: 5 set. 2021. 
SOUZA, Pedro Henrique et al. . Os Efeitos do Programa Bolsa Família sobre a Pobreza e a Desigualdade: Um Balanço dos Primeiros 15 Anos. Texto para Discussão, n. 2499, Brasília: Ipea, 2019. Disponível em: https://bit.ly/3kWnQfy. Acesso em: 5 set. 2021.

ZUCCO, Cesar; POWER, Timothy. Bolsa-Familia and the Shift in Lula's Electoral Base, 2002-2006. Latin American Research Review, 48(2), 2013. Disponível em: www.jstor.org/stable/43670073. Acesso em: 5 set. 2021. 